\title{
Mobile Spatial Information Service Based on Intelligent Map Agent
}

\author{
Zhanya XU, Xincai WU \\ Faculty of Information Engineering, China University of Geosciences, Wuhan, Hubei, China
}

\begin{abstract}
This paper analyzes the existing spatial structure of mobile information services and the current new characteristics of the service, proposes a new service model. The model adopts a unified deployment solution of spatial data. It extends the spatial data management and lightweight computing to the embedded computing devices, and enhanced the service flexibility and scalability. The design of mobile side achieves the integration of spatial data management, mobile computing and wireless communication, and it can meet the various needs of spatial information mobile services. The paper introduces the composition of the new model and the key contents, and pointing out that this model is the inevitable trend of spatial information mobile services.
\end{abstract}

Keywords: mobile agent; intelligent map agent; mobile spatial information service

\section{基於智慧地圖代理的移動空間資訊服務}

\author{
徐戰亞, 吳信才 \\ 中國地質大學 資訊工程學院，湖北 武漢
}

\begin{abstract}
摘 要: 本文分析了現有移動空間資訊服務架構和目前新的服務特性，提出了一種新的服務模型。該模 型採用了統一的空間資料部署方案，將空間資料管理和羽量級的資訊計算擴展到了嵌入式終端，增強 了服務的靈活性和擴展性。模型在移動端實現了空間資料管理、移動計算、無線通信等內容的集成, 能夠滿足移動空間資訊服務的各種需求。論文詳細介紹了這種新的服務模型的組成，並對其關鍵內容 設計進行了講解，並指出了這種模型是移動空間資訊服務發展的必然趨勢。
\end{abstract}

關鍵字: 移動代理；智慧地圖代理；移動空間資訊服務

\section{1. 前 言}

空間資訊服務是以 4A（ anytime, anywhere, anybody, anything）服務為目標[1]，結合空間信息技術、 定位技術和互聯網技術, 針對目標物件所提供的與行 業應用和大眾生活等緊密相關的各種綜合服務。目前 的空間資訊服務的主要方式是空間資料在伺服器端集 中式或分散式管理, 利用 SOAP 和 WebService 等技術 完成空間資料與應用資料的傳輸。這種服務在已經在 很多領域得到了廣泛應用。隨著智慧移動設備的普及
和發展, 與生俱來的定位能力及無線資料傳輸能力使 得智慧移動終端成為了空間資訊服務中的重要組成部 分。結合了移動通信、移動計算、高精度定位等內容 的移動空間資訊服務也成為一個重要的研究方向 [2]。但是一直以來, 移動終端都主要作為資訊服務的 表現端，另外，移動空間資訊服務的物件是各種行業 用戶和大眾用戶，基於 mobile-agent 的空間資訊服務 模型[3]在實施過程中有著很大的不確定性，資料與服 務的多樣性需求在移動端上很難實現複雜的應用邏 輯，因此，空間資訊服務的在移動端的應用部署上， 
有著很大的限制於不足。另外, 隨著嵌入式技術的發 展, 它對現有的移動空間資訊服務產生了很大的影 響。移動終端在運算能力、顯示性能及通信能力的增 強，使得現有的服務架構產生了新的局限。

智慧地圖代理（Intelligent Map Agent）是一種基 於 Agent 技術所實現的能夠對各類空間資料進行動態 組織、控制、加工與計算的服務框架[4]。它可以適用 於各種移動用戶, 並且服務的內容也包含大範圍的地 理資料。同時, 利用無線通信技術, 使得服務的範圍 更加廣泛和深入。本文根據移動端所具備的新特徵, 基於智慧地圖代理設計了適用于智慧移動終端的移動 空間資訊服務模型, 將空間資料與應用資料進行分類 管理, 在伺服器端和移動端進行了空間資料和應用資 料的統一的部署, 實現了功能在移動端的遷移, 並利 用這種模型, 設計了資訊服務在移動端的通用解決方 案。

\section{2. 現有移動空間資訊服務分析}

移動空間資訊服務能夠對各種空間資料進行有 效管理, 並根據應用需求, 以靈活的方式提供資訊服 務, 將空間資料和服務資訊通過 Internet 和無線網路 提供給用戶端。常見的服務架構通常採用基於層次式 的空間資訊服務結構[5], 這種結構將空間資料管理 與空間資訊服務管理相分離, 通過對服務層的強大資 料管理與空間分析的能力來完成空間資訊服務的快 速部署與擴展相分離的方案來實現應用的快速擴 展。另外, 基於 mobile-agent 的移動空間資訊服務結 構在層次是架構上做了深度擴展[3], 它採用了核心 服務層與企業應用服務層相分離的方案, 將更多的空 間資訊服務處理放在核心服務層, mobile-agent 在服 務端完成計算、通信、安全、定位、表現等工作，同 時在中間層又完成了通信、服務定位、相互間通信等 工作, 這種架構中, Mobile-agent 作為獨立的計算單 元完成各項計算任務來即時靈活地擴展及增強了在 移動端上的空間資訊服務。Mapinfo 與 ESRI 及 AutoDesk 等公司的空間資訊服務平臺的設計中, 針 對移動端的服務也分別給出了自己的解決方案, 但基 本的結構都是 WebGIS 服務端與移動用戶端的集 成, 空間資料都是通過無線通信進行傳輸, 移動用戶 端主要進行定位、服務請求與資訊視覺化, 同時也可 以進行一定的移動計算[6]。

但這些架構所完成的僅僅是將空間資訊服務從有 線網路到了無線網路的遷移, 大資料量的空間資料與 不可靠的無線網路傳輸在這些架構中没有被很好的考
虑與解決, 空間資訊服務的多樣性與擴展都僅僅在服 務端和中間服務層進行擴展, 用戶的各種應用需求很 難得到有效滿足。熊和邊提出了基於用戶端的空間資 訊服務體系結構[7], 在這種結構中, 移動端利用自身 的存儲能力, 用壓縮等技術在用戶端用嵌入式資料庫 進行空間資料的存儲, 同時還設計優化顯示模組、移 動計算模組和空間資訊模組。這種結構以嵌入式資料 庫為核心完成了空間資訊服務在移動端的部署, 使移 動用戶端具備了一定得自主能力是實用性, 但是對於 空間資料的變更和資料的統一性没有考虑, 使得服務 的範圍小, 適應性差。另外, 這種結構對於快速增長 應用需求是不合適的, 資料量的迅速增加將使得服務 無法開展。

\section{3. 移動空間資訊服務的新特點}

與先前的移動空間資訊服務相比, 隨著資訊服務 方式與網路技術的發展, 新的移動空間資訊服務出現 了很多新的特徵：

1)基於移動端的空間資訊服務逐步成為資訊服務 的主流, 從大眾生活到行業應用, 基於移動端的空間 資訊服務需求越來越多, 對服務的內容需求程度差異 越來越大;

2)基於位置的 GIS 相關的服務需求逐漸淡化, 與 位置相關的綜合資訊服務等已經成為目前資訊服務的 新的增長方向, 如餐飲、行車、天氣、旅行等等;

3)資訊的視覺化的需求的增強, 不再是僅僅文字 或圖片上的資訊視覺化, 而是需要更為豐富的操作性 和美觀性;

4)以無線資料傳輸為主要途徑的資訊的即時傳輸 與獲取;

5)4A 服務的需求在精度、即時性等方面的進一步 增強。

針對上述特徵, 可以總結出新的空間資訊服務的 主要關鍵內容如下:

1)空間資料的多樣性需求的提高, 資料不僅僅依賴 於已有的空間資料, 更多的行業資料和與空間實體無關 的資料將是空間資訊服務資料增加的最多的內容。

2)資訊服務內容的多樣性的提高, 移動終端的應 用需求的增加, 使得需要將更多的計算和處理在移動 端來完成, 而移動端也需要能夠對各種多樣化的需求 進行快速的應用擴展。

3)視覺化引擎的需求, 不僅僅是服務資訊的視覺 化, 地圖的視覺化與交互性也是空間資訊服務的一個 特徵, 且需要能夠在低解析度的顯示幕上完成豐富的 
資訊顯示和便捷的操作交互。

4)設計合理的空間資料管理模型, 真正降低無線 資料傳輸的資料量, 完成資料和移動端和伺服器端進 行合理的綜合部署。

\section{4. 基於 IMA 的移動空間資訊服務模型}

由上述的分析可以看出, 移動空間資訊服務的普 及性與移動終端的發展是密不可分的, 服務的請求發 送、接收, 應用資料的接收、顯示, 資訊的視覺化和 互動操作均是在移動端完成, 因此, 移動端的快速, 也推動了移動空間資訊服務的發展。根據嵌入式系統 的技術發展和技術特徵, 移動端在目前的移動空間資 訊服務中佔據了越來越重要的地位, 因此在新的服務 框架中, 越來越多的服務內容和邏輯開始發生一定的 遷移。

\section{1 基於 IMA 服務模型組成}

基於智慧地圖代理的移動空間資訊服務模型是以 用戶的應用需求為中心的, 提供統一的無差異空間資 訊服務, 並對各種服務的領域和內容統一的富移動端 應用框架模型, 將空間資訊服務從基於 Internet 的 PC 或伺服器端過渡到了基於無線通信的移動端。這個架 構 ( 見圖 1 ) 中的三個主要模組分別是: 資料管理層、 服務中間層和用戶端層。

\section{$\mathrm{A}$ ：資料服務層}

資料管理層負責整個資訊服務中所有的空間資料 的管理, 它以統一的空間索引為基礎, 將不同應用相

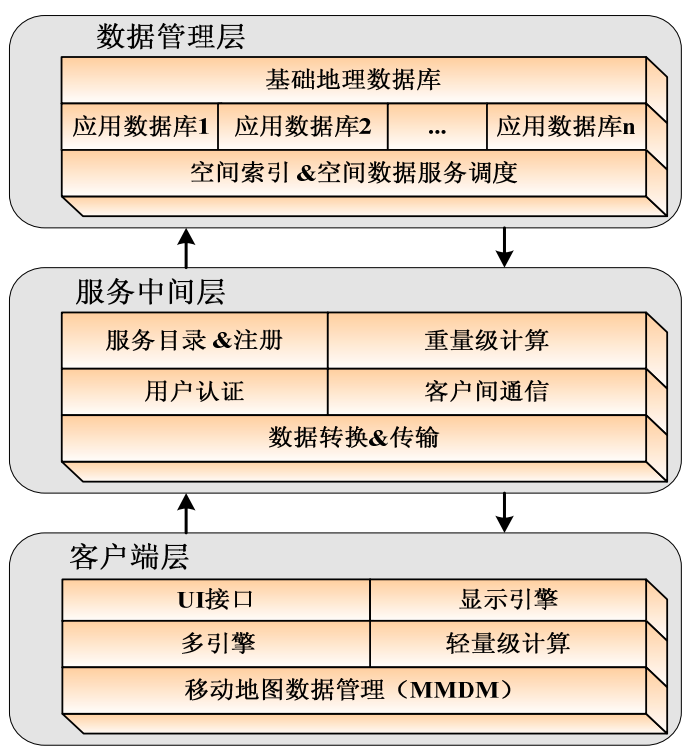

圖 1. 基於 IMA 的移動空間資訊服務模型
關的各種資料進行集中或分散式管理, 對服務中間層 所提交的各種資料請求進行統一調度，從不同的資料 庫中按用戶所請求的內容進行處理並將結果資料返回 給服務中間層。它是整個空間資訊服務的基礎。

\section{$\mathrm{B}$ : 服務中間層}

服務中間層是這個空間資訊服務的核心，它主要 負責各種應用的註冊與管理，提供給資訊服務端的各 種授權，也完成各種移動端間的資訊傳輸與交換，同 時, 根據不同的應用需求, 完成不同應用中的各種重 量級空間計算，最後根據用戶端的種類，將運算的結 果和空間資料進行轉換處理並以無線等方式完成傳 輸。

\section{C：用戶端層}

用戶端模型設計是這個空間資訊服務架構模型中 的核心，它與資料管理層有著類似的空間資料管理結 構, 但資料格式又有不同，它採用適合移動端的物理 存儲格式, 能夠在低性能和低存儲量的移動端上完成 各種快速的流覽和交互操作，這個資料由服務中間層 來生成。另外，用戶端中還採用了多引擎結構來支援 一些羽量級的移動極端和空間分析，利用這種結構， 可以徹底改變以往的移動端的單一性特徵, 使得移動 端成為資訊服務的移動計算單元，豐富的資訊視覺化 與計算能力能夠使空間資訊服務在移動端得到快速的 推廣與擴展。

\subsection{IMA 用戶端模型設計}

移動端模型是整個空間資訊服務的核心，隨著 GIS 的應用的發展, 應用越來越多開始往移動端遷 移，針對這些特點，移動端的設計重點包括下面一些 內容:

\section{A：移動地圖資料管理}

對應於空間資料管理，移動端也採用類似資料管 理層的方案對資料進行統一管理 (MMDM), 在本地 完成空間資料、遙感資料和應用資料的統一管理，且 所有的資料都以嵌入式所適合的擴展的物理存儲格式 來進行存儲, 來解決存儲量和資料訪問性能等問;

B：應用資料管理

應用相關的資料採用嵌入式資料庫或檔方式進行 存儲，應用資料可以與資料管理層進行資料交換，來 獲取即時的資料或進行內容更新，這些資料可以實現 共用, 另外, 借助於服務中間層, 可以實現移動端在 服務中間層級別的資料通信和資料交換，可以大大提 高工作的協作性和主動性。

\section{C：移動計算的深度應用}


在移動端為了保證應用的快捷與高效, 需要將移 動計算在多個方面進行擴展, 首先是視覺化引擎的設 計, 這個應用主要用來負責完成各種資料的視覺化管 理, 在移動端的資料管理中, 利用引擎來完成高效率 的向量地圖顯示、高性能的應用資訊視覺化以及遙感 資料與向量資料的疊加顯示。另外, 在各種行業應用 中，利用資料分層管理的思想來實現各種資料的定制 顯示；其次是羽量級 GIS 引擎的引入，利用對向量資 料的管理中的各種高效空間索引, 完成各種資訊檢索 和查詢, 包括路網分析等, 將更多的 GIS 功能在移動 端實現, 更好地支持各種應用的需求。最後是 $3 \mathrm{~S}$ 的 深度集成, 作為與生俱來的定位能力, GPS 的定位能 多也很大地促進了嵌入式終端的普及, 但是 GPS 的精 度在某些應用中遠遠不夠, 因此需要利用一些手段來 增強, 如遙感影像的疊加顯示可以很好提高各種資料 獲取的效率和精度, 特別的是, 在導航應用, GPS 資 料和道路拓撲資料相結合的地圖匹配技術也能更好地 增加定位的準確定和精度。

$\mathrm{D}$ ：應用模型的設計

作為各類資訊服務的移動端, 面臨的應用是多樣 性的, 為了滿足不同行業和領域的需求, 需要提供一 個統一的應用模型來快速完成各類應用軟體的設計, 這種設計應該是脫離於各類嵌入式作業系統和硬體 的, 且應該能夠適應不同的領域需求。在本文中, 採 用的是層次式模組化結構, 它從底層的作業系統層到 最上層的應用層都具備了相應的設計, 這種設計可以 很好地適用於各種硬體結構和應用需求, 並且模組化 的設計很大地提高了應用的靈活性, 因此能夠很快地 進行各種擴展。

\section{5. 部分關鍵內容設計}

基於 IMA 的移動空間資訊服務與先前的服務相 比, 主要的變化集中在了移動端的設計上, 隨著智慧 移動終端的快速普及和發展, 移動終端已經開始具備 相當的運算能力和資料的管理能力, 因此, 除了增強 移動端的羽量級計算與邏輯處理引擎之外, 空間資料 的管理和存儲同在整個模型中得到了增強。下面對空 間資料的部署和用戶端的應用集成設計和服務流程做 簡要介紹。

\section{1 空間資料的統一部署方案}

空間資料是移動空間資訊服務的必要組成部分, 資訊的視覺化需求的提升對空間資料的要求也越來越

\begin{tabular}{|c|c|c|c|c|c|}
\hline 应用 & \multicolumn{5}{|c|}{\begin{tabular}{|c|c|c|c|} 
导航 & 巡检 & 勘测 & 物流 \\
\end{tabular}} \\
\hline 多引擎 & \begin{tabular}{|c|} 
滑动 \\
要素
\end{tabular} & $\begin{array}{l}\text { 标注 } \\
\text { 详情 }\end{array}$ & & & 定位 \\
\hline \multirow{2}{*}{$\begin{array}{l}\text { 移动地 } \\
\text { 图数据 } \\
\text { 管理 }\end{array}$} & $\begin{array}{l}\text { 空间 } \\
\text { 数据 }\end{array}$ & 遥感 & $\begin{array}{l}\text { 拓扑 } \\
\text { 道路 }\end{array}$ & POI & $\begin{array}{l}\text { 缓冲 } \\
\text { 数据 }\end{array}$ \\
\hline & \multicolumn{5}{|c|}{ 物理存储格式+嵌入式数据库 } \\
\hline \multicolumn{6}{|c|}{ 嵌入式操作系统 } \\
\hline
\end{tabular}

圖 2. 基於 IMA 的用戶端結構

高, 精度和覆蓋範圍也越來越大, 當大量的用戶端進 行服務請求的時候, 資料管理層的伺服器將時刻面臨 巨大的負載，同時大資料的傳輸也會給無線網路帶來 很大負擔。移動終端存儲能力的提升可以使得這一現 象得到緩解，但是如何在資料管理端和用戶端部署統 一的空間資料也是目前面臨的巨大問題。

通常的移動端的空間資料存儲都會採用國際通用 的物理存儲格式來實現大資料量的存儲, 同時這些格式 也可以大大提升資料的訪問性能和索引性能 對於圖片 加資訊點的服務方式雖然能夠滿足多數的需要, 但是單 一的點資料管理很難滿足行業用戶的需求, 缺乏對空間 資料的管理也會降低服務的靈活性和通用性。

在本模型中，空間資料的部署主要由中間層來協 調完成。所有的空間資料在伺服器端採用了統一的管 理，且各種應用資料都通過唯一的空間索引來和基礎 地理資料相關聯。這種統一的空間索引，也是移動端 進行空間資料請求的唯一依據。移動端可以通過多種 方式, 來預先從伺服器獲得此部分基礎地理資料, 也 可以即時發送資料的請求，所有的這些資料都會在中 間層進行格式的轉換，以物理存儲格式的方式傳給用 戶端。在這個過程中，不涉及任何應用資料庫。

在應用過程中，由於基礎地理資料的相對持久 性, 資料的更新頻率極低, 而應用資料是相對多變的, 因此，每次服務的過程中，參與的資料以應用資料為 主, 且資料量小，內容單一。這樣的設計將會大大減 少應用過程中的資料的傳輸過程, 將更多的計算放在 了應用服務的處理上。

\section{2 用戶端應用集成設計}

移動端應用集成是這個框架中的重點，它不僅負 責移動端空間資料和應用資料的管理，也承擔所有羽 量級的 GIS 的功能。在資料管理的基礎上，利用向量 地圖, 配合主動的 GPS 定位或被動的無線定位來增加 定位的精度和效率; 在多引擎結構的基礎上, 完成地 
圖與應用資料的視覺化; 根據應用的需求, 即時向服 務中間層發送資料請求，獲取即時資料，同時也可以 利用這種方式與其他移動端進行通信。這種移動端的 集成方案不仅减轻了服務端的負載同时也增加了結構 的複雜度。移動端对大量的数据存儲也增强了利用移 動計算來提升移動終端的獨立性和处理異常通信的能 力，因此，更適合做通用的資訊服務終端。

\section{3 用戶端的服務流程設計}

基於 IMA 的用戶端能夠對空間資料和應用資料 進行獨立地處理和分析能力, 當本地資料不能滿足需 求時, 會即時通過無線網路與中間層通信, 以從伺服 器端獲取準確的資料, 並完成資料接收, 最終在本地 完成應用資料的加工與視覺化顯示。

當運算量過大時, 用戶端可以將服務請求發送到 中間服務層, 由中間服務層來完成計算, 並將結果返 回給移動端。這樣, 移動端負責服務資料的最終處理 與整合, 並將資訊視覺化, 顯示給用戶。下圖是基於 IMA 的用戶端進行業務處理的基本流程。

\section{6. 結論與展望}

隨著嵌入式硬體的發展和資訊服務程度的提升, 基於移動端的空間資訊服務將成為未來數位城市和數 位地圖的主要服務方式, 本文根據嵌入式硬體的特 性, 從伺服器端到移動端對空間資料的管理、GIS 功 能的遷移和移動端的智慧應用邏輯等幾個方面進行系 統的分析, 設計完成了基於智慧地圖代理的空間資訊 服務框架。與以往的空間資訊服務框架相比, 該框架 有以下主要特徵:

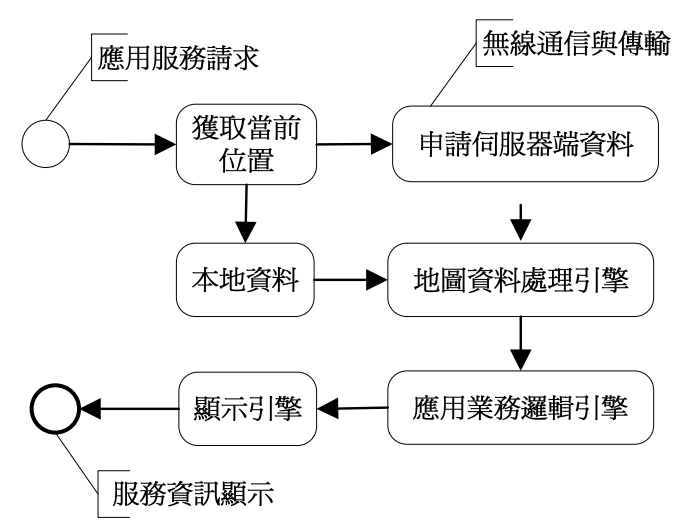

圖 3. 基於 IMA 用戶端的服務流程圖
1)根據 GIS 應用的物件和內容需求的變遷將 GIS 應用從伺服器端真正延伸到了移動端, 將大量的羽量 級 GIS 應用靈活部署在移動端，同時，移動端對空間 資料和應用資料的管理方案可以有效地增強了移動端 的資訊處理能力和應用的靈活性，同時也大大減少了 服務端的負載。將移動端作為了空間資訊服務的主體。

2)移動端的多引擎結構與 GIS 模組的管理模型 是種層次式可擴展應用模型, 它將空間定位、移動計 算和無線通信等特點在移動端進行了很好的集成, 這 種靈活的結構能多適用於各種領域的資訊服務需 求, 能夠提供一個統一的面向全領域的高性能移動空 間資訊服務移動平臺，並能夠在這個結構上快速開展 各種應用部署和擴展, 便於移動空間資訊服務快速普 及。

3)空間資料在移動端的空間資料管理方案，減少 了常規移動空間資訊服務的無線資料傳輸量, 減少了 服務中的不確定風險，提高了服務的性能和效率，同 時大大減少了應用伺服器和資料伺服器的計算量, 增 強了應用部署的適應性和實用性。

隨著 GIS 的應用的深入和空間資訊服務在生活中 的普及，更多的基於移動終端的資訊服務需求將被提 出, 新技術的發展和將會給移動空間資訊服務注入越來 越多的活力, 本文所設計的模型僅完成了服務的模型設 計, 在實際的應用中還有很多部分有待擴展和加強。

\section{參考文獻 (References)}

[1] 李德仁, 李清泉, 謝智穎, 朱欣焰. 論空間資訊與移動 通信的集成應用[J]. 武漢大學學報·資訊科學版, 2002， 2, 1-7.

[2] 李琦, 史文勇, 林宇. 一種新的移動空間資訊服務系統 的體系結構[J]. 地理與地理資訊科學, 2003, 7, 45-48.

[3] 方志祥. 李清泉. 基於 Mobile Agent 技術的空間資訊 移動服務[J]. 測繪學報, 2004, 4, 328-333.

[4] E. Gervais, H. Liu, D. Nussbaum, Y. S. Roh, J. R. Sack, and J. Yi. Intelligent map agents-A ubiquitous personalized GIS. ISPRS Journal of Photogrammetry and Remote Sensing, Special Issue on Distributed Geoinformatics, 2007, 347-365.

[5] 王濤, 張永生, 張轞. 一種移動空間資訊服務系統用戶 端的設計與實現方法[J]. 2006, 9, 49-52.

[6] 張海棠. 空間資訊移動服務模型 演算法與傳輸技術研 究[D]. 中國人民解放軍資訊工程大學, 2005, 4.

[7] 熊慶文, 邊馥苓. 基於嵌入式資料庫系統的移動 GIS 應用體系結構研究 [J]. 武漢大學學報·資訊科學版, 2006, 1, 86-89. 